\title{
Advanced IT Education for the Vision Impaired via e-Learning
}

\author{
Helen L. Armstrong \\ School of Information Systems, Curtin University of Technology, \\ Perth, Western Australia, Australia
}

h.armstrong@curtin.edu.au

\section{Executive Summary}

Lack of accessibility in the design of e-learning courses continues to hinder students with vision impairment. E-learning materials are predominantly vision-centric, incorporating images, animation, and interactive media, and as a result students with acute vision impairment do not have equal opportunity to gain tertiary qualifications or skills relevant to the marketplace and their disability. Due to its logical, rather than physical, nature IT help desk and network administration roles are ideal for people who are blind. This paper describes the development of a fully accessible e-learning environment to deliver advanced IT network curriculum to adults with acute vision disabilities. The components include a virtual classroom, accessible learning materials, a remote computer laboratory, and delivery of the learning materials by vision impaired instructors. Industry standard courses in advanced IT were redeveloped, and the accessible on-line learning environment was developed to deliver the courses. Vision impaired students who excelled in the pilot project were trained as instructors, gaining industry-standard instructor certifications. These instructors were used to assist with the design of accessible methods and delivered the materials to the vision impaired students.

The project has been operational for four years with a pilot project being conducted over a two year period, followed by the delivery of the courses both local and remote vision impaired students across the globe using this accessible e-learning environment for the past two years.

Evaluation results indicate that vision impaired students situated both locally and remotely gained equivalent grades to their sighted counterparts given additional time to comprehend and experiment via the virtual classroom and remote computer laboratory. In addition, the use of vision impaired instructors has resulted in more innovative approaches to accessible teaching methods and delivery of the curriculum.

Keywords: vision impairment, network administration, e-learning, accessibility, IT certification.

\section{Introduction}

\footnotetext{
Material published as part of this publication, either on-line or in print, is copyrighted by the Informing Science Institute. Permission to make digital or paper copy of part or all of these works for personal or classroom use is granted without fee provided that the copies are not made or distributed for profit or commercial advantage AND that copies 1) bear this notice in full and 2) give the full citation on the first page. It is permissible to abstract these works so long as credit is given. To copy in all other cases or to republish or to post on a server or to redistribute to lists requires specific permission and payment of a fee. Contact Publisher@,InformingScience.org to request redistribution permission.
}

The vision-impaired continue to struggle to gain education in contemporary areas relevant to the market place and their disability. Technological progress has much to contribute to this state of affairs, with highly inaccessible computerization of many online educational courses. Educational institutions have been slow to ensure accessibility of learning materials and environments for 
those with a variety of disabilities, and the vision impaired are particularly disadvantaged by the vision-driven online education approach (Harper, Goble, \& Stevens, 2001). In the context of this discussion the term 'vision impairment' refers to a vision disability resulting in little or no useful vision. In the past this type of disability would have been referred to as blindness. The learning environment developed was designed for students who have acute vision impairment and are medically certified as legally blind.

E-learning approaches in the IT field generally have had mixed success with some authors reporting that student learning was not enhanced by this approach (Sweat-Guy \& Wishart, 2008) and others arguing that this mode of instruction is just as effective as face-to-face teaching (Boghikian-Whitby \& Mortagy, 2008) and provides increased student learning and satisfaction (Yip, 2004). While e-learning and web-based applications have opened opportunities for many students, including those with disabilities, they remain primarily vision dependent. In line with the progress in visual technologies there has been a noticeable increase in the use of graphics, images, and animation in the presentation of e-learning materials across the board. The nature of elearning materials in the sciences and technology is predominantly vision-centric, incorporating large amounts of diagrams, color images, visual cues, and animation (Kelley, Sanspree, \& Davidson, 2000). This trend presents the greatest challenge to vision impaired students in engineering and computing disciplines where inability to access the learning materials (Armstrong \& Murray, 2007) contributes to the digital divide for students with vision disabilities.

This paper describes a project to develop a fully accessible e-learning environment for teaching advanced IT to the vision impaired. This environment consists of accessible e-learning materials, a virtual classroom, and a remote virtual network for the design and testing of computer network architectures. Two totally blind instructors presented the learning materials assisted by a sighted teaching assistant. An international industry-standard training program using reliable online learning delivery was used for testing the technology-driven learning and teaching. The Cisco Network Academy Program (CNAP) computer networking online training program was used as the foundation, converting the associated online materials into formats accessible to people with blindness and acute low vision. The CNAP online courses were chosen as they are industrystandard certification courses, providing the vision impaired students with relevant qualifications currently in demand by employers. IT certifications are highly regarded by employers and provide students with confidence of their abilities (Hunsinger \& Smith, 2008). The CNAP courses also form the basis of several undergraduate courses in a Bachelor of IT program, thus providing articulation into an undergraduate degree for those wishing to continue their studies. Additional components were developed to form a totally integrated e-learning solution for the vision impaired students. The end product offers the vision impaired skills and knowledge in IT networks, industry-standard certification in an area relevant to their disability, and provides a path to further education and employment. The process, methods and tools are explained. Results of an evaluation of the success of the project using student grades achieved and interpretive views of the vision-impaired students are also discussed.

\section{Vision Impairment and Inclusive Education}

Equal opportunity legislation in many nations state that people with disabilities have access to the same opportunities as others. Unfortunately there still exists a digital divide that separates people with disabilities from achieving the equal opportunity and equal access they seek. Higher education institutions are increasingly using web pages and Internet resources for essential learning materials, and with the growing number of vision impaired students studying at these institutions accessibility issues are of paramount importance (Thompson, Burgstahler, \& Comden, 2003). However, numerous research projects report the majority of web sites visited are not accessible (Mankoff, Fait, \& Tran, 2005; McEwan \& Weerts 2007; Thompson et al., 2003). Inaccessible 
web materials promote an educational divide where people with disabilities are denied equal access to public education (Kane, Shulman, Shockley, \& Ladner, 2007), and as a result the opportunity for education for people with disabilities is less equal than that for able-bodied people.

As a cohort, people with disabilities are among the least considered in the educational context of online learning (Kinash, Crichton, \& Kim-Rupnow, 2004). Past research has shown that the blind lack intellectual power due to challenges to access and participate in educational institutions (Hogan-Royle, 2006), with the most significant barriers to inclusivity in education being the lack of inclusive mindset, lack of knowledge about pedagogy, high teaching loads, and lack of time for instructional development (Moriarty, 2007). Other explanations include web designers having little or no accessibility experience and a lack of information about the best ways to quickly and easily identify accessibility problems (Mankoff et al., 2005). Accessibility groups are active in research in the challenge to fill these gaps; however, there is a long way to go before accessibility considerations are routinely included at the design stage of online and remote learning web sites.

\section{Vision-centric Learning and Teaching}

The dominance of the sense of vision has been the focus of much research (for example, Thesen, Vibell, Calvert, \& Osterbauer, 2004 and Spence, Kettenmann, Kobal, \& McGlone, 2001). Of the body's five sensory inputs, vision is the key sense used in learning. Vision also modifies or dominates the interpretation from the other senses where there is variance between the inputs from more than one sense (Shore \& Klein, 2001). Low vision and totally blind students must rely on input from physical senses other than sight; however, most e-learning environments generally assume the learner has sight. Fenrich (2005) suggests that by utilizing simulations, active experimentation, discovery-learning techniques, questioning with feedback, video, animations, and photographs, practical hands-on skills can be taught virtually. This may be the case for sighted students; however, vision impaired students do not have the sight needed to access many of these multi-media sources of delivery. Care needs to be taken with navigation, structure, content design, and communication aspects in online learning environments for students with disabilities (Pearson \& Koppi, 2002).

Before discussing the methods trialed it is important to understand the obstacles faced by students with a severe vision disability studying in the areas of IT, computer science, and computer engineering. The first learning obstacle is the concentration of visual presentation of core learning content. Recent progress in technology has enabled teaching methods to move from predominantly textual forms to visual content and web-based modes of delivery. Many tertiary education institutions now incorporate industry-standard IT courses into their curriculum to aid employment of their graduates. A review of the Cisco and Microsoft e-learning materials reveals large amounts of tabular data, photographs, graphs, and charts in numerous formats (line graphs, bar charts, pie charts, etc), color diagrams, animation, drag and drop, buttons and icons, plus a variety of interaction methods. In most cases the sighted student can easily recognize 'the thousand words' inherent in an image; however, these are seldom supported by either a detailed textual description of the image or a discussion of the message being portrayed. Of concern in specialist fields such as computing are the effects of vision impairment on the student's ability to comprehend essential parts of the curriculum, normally taught using visual means. Education materials in IT-related disciplines traditionally rely heavily on tables and graphics to present essential concepts, methods, and architectures. Blind students cannot see diagrams and low vision students have great difficulty comprehending what is being taught. The challenges of developing learning materials for the vision impaired and interfaces not reliant upon graphics are complex (Sánchez, 2007). Vision impaired students are increasingly being disadvantaged as teaching environments move to integrate more vision-centric methods of presentation within e-learning materials. In- 
structional designers need to be cognizant of the difference in needs between totally blind students, students with some useful vision, and students who are sighted.

The second learning obstacle for blind and low vision students is that the majority of web-based content is not designed for assistive technologies, and as a result assistive technologies can be frustrating to use. The assistive technologies readily available to students with severe vision impairments are Braille display devices, screen enlargement software (such as Magic and Zoomtext), and screen reading software that converts text into audio (such as Jaws). These commonly used assistive technologies have limited or no ability to translate graphical images. Computerbased visualization techniques depend almost entirely on high-resolution graphics, and for visionimpaired users the problems of using complex visual displays are great. There are currently only limited methods for presenting information non-visually, and these do not provide an equivalent speed and ease of use to their graphical counterparts. The assistive technologies used by vision impaired and blind students may translate this information incorrectly, or not at all, leading to incomplete, erroneous, or different interpretations of concepts presented. Although research projects in the development of assistive technologies are frequently presented in the literature, the development of haptic, force-feedback, and other sophisticated technologies are still in their infancy, being environment dependent and requiring large amounts of code development and testing. While computer-based learning has opened opportunities for many students with disabilities, it remains primarily vision dependent.

The need to play and experiment in a computer environment is vital to the learning process and presents the third obstacle to those with an acute vision disability. Practical application, in contrast to didactic learning, has been presented as an essential part of the learning process dating back to Aristotle. Learning theories by Kolb, Lewin, and Piaget emphasize the need for practice, claiming experience assists in the assimilation of new knowledge and thus solidifies learning. In many cases vision-centric e-learning materials are designed to replace experiential learning previously achieved by practical application. As students with vision impairment tend to use their memory to a greater extent than their sighted counterparts, practical experience is even more crucial to concrete their learning. Students learn by processing materials via different 'lanes' to the brain (Sprenger, 1999), and experimenting in a familiar and trusted environment allows blind students to use multiple lanes to the brain, including the physical senses, experiences, and emotional reinforcement, aiding comprehension.

The above learning obstacles, together with the lack of truly accessible e-learning education and the nature of sight disabilities means higher education and training institutions must move to more relevant multi-modal user interfaces in order to make e-learning materials more accessible to all students.

\section{Methodology}

The aim of the project was to present to acutely vision impaired people accessible IT networking training equivalent to that offered to sighted people. As a result the vision impaired would have a greater opportunity to undertake tertiary education and be better skilled for employment in IT roles in industry.

IT network skills are deemed relevant to the vision impaired for several reasons. Firstly, the majority of interaction with networks and computer workstations at the operations level is via command line. Command line uses text input and output, and text is easily converted into audio output by screen reading software. Second, although the physical network may involve wiring, IT networks are logically configured and network management and support is carried out logically via a workstation. This means that vision impaired IT personnel do not need mobility to physically visit the user's workstation to carry out support functions. Finally, as this disability group 
use computers and the Internet as a lifeline to colleagues and friends, these skills are required to not only support an employer's computer network, but also allow the vision impaired to be less reliant on others to fix their own computer systems.

In order to achieve the aim of the project it was necessary to build a training environment that was fully accessible to the vision impaired and to deliver an IT networking course to these students. Sighted students enrolled in the same course, sitting the same assessments, were used as a control group for purposes of comparison. If the vision impaired students (using redeveloped accessible learning materials and delivery methods) achieved results within $5 \%$ of the sighted students (using original learning materials designed for the sighted) then the project would be deemed successful.

A pilot project was carried out to investigate the most effective means of making an IT networking course fully accessible to the vision impaired students. Cisco IT network training courses were chosen as the vehicle for the redevelopment. Cisco networking skills are in high demand and are recognized as an international industry-standard. The pilot project included participants who were totally blind and those with a small amount of usable vision; however, all were classified as legally blind, receiving a blindness pension. The pilot project would test the effectiveness of numerous accessible methods and tools and integrate the most effective into an accessible learning environment.

\section{The Pilot Project}

A pilot project was conducted over a two year period, and the project went live in the third year. The pilot involved 19 legally blind students (all with $<5 \%$ visual acuity and/or $<10^{\circ}$ field of view) progressively testing converted versions of the Cisco Certified Network Associate (CCNA) elearning materials. The participants were recommended by the local Association for the Blind. To be considered the low vision participants needed to be 18 years or older, have a working knowledge of the chosen assistive technologies, possess a basic familiarity with computers, and have a willingness to learn.

Methods used in the conversion of the e-learning materials were based upon techniques described in the literature and guidelines specifically for this disability group, plus a substantial amount of exploratory work as the pilot progressed. Cisco Systems Inc donated the required network equipment; however the pilot project was unfunded and relied upon voluntary academics to develop and teach the converted materials.

As in the live implementation stage to follow, the subjects were split into two groups, a sighted set of students forming a control group not exposed to the redeveloped accessible content and methods under evaluation and the second set of vision impaired students exposed to these methods for purposes of comparison.

Evaluation of the extent of accessibility of the Cisco e-learning materials at the commencement of the project (before any redevelopment work had commenced) reported that the assistive technologies used by the blind students enabled them to access no more than $20 \%$ of the regular Cisco e-learning materials. This result reinforced the need for alternative means of presenting these materials.

The results of the pilot were very encouraging. The pass mark in all Cisco examinations is $75 \%$, and the vision impaired students scored an average of $92 \%$ in the first set of examinations. This result was the same as the sighted students in the control group who also scored an average of $92 \%$. The standard deviations in grades for the two groups were also very similar. The success of this pilot inspired an expansion of the project into a sound deliverable program, and the use of vision impaired instructors to deliver the materials. 


\section{e-Learning Environment for the Vision Impaired}

As the objective of the project was to develop an e-learning environment specifically to meet the needs of vision impaired students the following components were established:

1. A virtual classroom accessible by both remote and local students, and a physical classroom on campus for local students.

2. A remote laboratory for computer network design and testing.

3. Fully accessible curriculum consisting of a comprehensive set of online learning materials.

4. Delivery by trained vision impaired and sighted instructors, and specially designed teaching aids.

A profile of each student's vision impairment was considered and their use of assistive technologies to determine individual needs in the light of the learning objectives set. Although all the students in the class were legally blind, they displayed a range of vision disabilities. These profiles assisted in identifying needed resources and provided input to the planned teaching strategies.

\section{Classroom Environment}

The classroom environment comprised a virtual classroom utilized by remote and local students and a physical classroom for local students and instructors. The virtual classroom included a broadcasting and call management application enabling instructors to broadcast lectures and tutorials to local and remote students. The VoIP call management systems trialed were Cisco CallManager (http://www.cisco.com/en/US/products/sw/voicesw/ps556/), and Ventrilo (http://www.ventrilo.com/); however, apart from cost no discernable difference was noted between the products, both providing an acceptable level of service. It was necessary, however, to have a sighted teaching assistant manage the broadcasts as the status of listeners requesting interaction was driven by radio buttons on a visual display not accessible by screen reading software. Students logged in to the virtual classroom to listen to the lectures and participate in the tutorial exercises. The virtual classroom provided the facilities for students to talk to one another as well as communicate with the instructors, similar to a normal classroom environment. The lectures were recorded and made available as audio files on the project website along with other teaching materials for easy access by the students at any time. Remote communications occurred via VoIP with most students using freeware applications such as Skype for one-on-one communication.

The physical classroom comprised workstations outfitted with assistive technologies (in the form of screen readers and screen enlargers), router bundles, network equipment for the remote laboratory, a network simulation tool, and a course management server. Additional haptic and touch assistive technologies were trialed; however none were able to provide the necessary granularity of output required. All students are also able to access the e-learning environment via the Internet and have access to the same materials and equipment as those students in the physical classroom. Remotely located vision impaired students are not disadvantaged as they cannot see what is going on in the physical classroom due to their blindness. This is an advantage where travelling to the physical classroom is a hurdle to vision impaired students.

\section{Remote Laboratory}

A remote laboratory was established to enable both local and remote students to test their network configurations. This laboratory physically consisted of several network bundles and three servers. Using VMWare to produce virtual networks, students were able to configure the network accord- 
ing to the plans developed using the network simulation tool and test these in an isolated environment.

This facility gave the vision impaired students an opportunity to experiment with different network designs and discover how changes would affect their network in a live environment. The remote laboratory also enabled students located remotely to have the same facilities as the students attending the physical classroom.

\section{Accessible Curriculum}

Over the four year period the project was under continuous development, with extension and enhancement of the content and delivery mechanisms and adjustments to each new version of the learning materials released by Cisco. By the final year the curriculum included four fully accessible Cisco courses: IT Essentials $1 \& 2$ and CCNA $1 \& 2$. These courses form the foundation for two undergraduate courses in a bachelor program, introducing the vision impaired participants to study at the tertiary level.

The four-course Cisco program was designed to be presented over a twelve month period and provided the students with skills to:

1. Install, configure, and operate computer networks,

2. Resolve networking issues, and

3. Build a computer and install different versions of industry standard operating systems.

On completion of the program the participants have the skills required for IT support positions in industry or embark on further tertiary education. The accessible teaching materials comprised:

1. Lectures delivered by blind instructors (live and audio)

2. Textual materials accessible by screen reading software

3. Diagram and picture descriptions

4. Tutorial exercises presented by the blind instructors,

5. Interactive modules for revision and

6. Accessible assessments (quizzes, tests and examinations).

The lectures were transcribed into Braille using a combination of Computer Braille and Unified English Braille code (UEBC). While much of the learning material can be presented using the contracted UEBC code a large proportion involved program code and technical matter requiring the letter-for-letter translation provided by Computer Braille. In today's generation of vision impaired youth Braille skills are not considered essential as screen reading applications can convert text to audio.

\section{Delivery and Teaching Aids}

One of the problems identified during the pilot project was that sighted instructors were not fully cognizant of the needs of vision-impaired students with relation to the presentation of concepts and materials. It was found that the vision-impaired students who had progressed to a more advanced level were able to explain these concepts in a manner the vision-impaired beginners could more easily assimilate.

Two totally blind instructors were then trained to deliver the Cisco course materials aided by a sighted teaching support officer. These blind instructors had first-hand experience of the difficulties encountered by the vision-impaired learner and were active in the design of effective ways of 
presenting the learning materials. Lectures and tutorials were broadcast via the virtual classroom by the two blind instructors to local and remote vision impaired students. The audio lecture files were stored on the course management server for subsequent student access. Due to the interactive nature of the virtual classroom remote students were able to ask questions during delivery of the lessons. Quizzes were conducted regularly to review understanding of the work covered and determine the effectiveness of the teaching methods. Low vision and blind students worked together with the teaching team to prototype effective methods of delivery.

Both sighted and vision impaired students used the same equipment and laboratories; however classes were scheduled at different times as the noise created by the sighted students made it difficult for the vision impaired students to hear the audio output from their screen reader applications. The number of students completing each intake was the same: 19 vision impaired and 19 sighted. Sighted instructors presented the classes to the sighted students and vision impaired instructors to the vision impaired students.

Manual teaching aids developed included pegboards to explain binary-hexadecimal-decimal conversions and IP addressing, and dominos and wire to illustrate network topography. Dominos are flat plastic disks molded to emulate the icons used in diagrams in the Cisco teaching materials. Each domino represented a network component (such as a router or switch) and each component was easy identified by raised markings on the top of each domino. Later in the project a network simulation software tool, iNetSim, was developed for the students to complete network design exercises. iNetSim was used specifically in teaching router configuration, network management, routing protocol configuration, and setting access lists to control access to routers. It allowed configuration of virtual network devices including routers, switches, hubs, and PCs, and each device was able to have several ports of different types including Ethernet, serial, and console. Connections between devices were created by specifying two ports to connect, plus a cable type. Removing a connected port disabled the connection the same way unplugging a cable would in a real network. A command line interface to devices provided control and feedback over the simulation. The interface acted in a similar way to the operating system for that device type, for example, a generic DOS-like system for PCs and Cisco IOS for routers (Hope, von Konsky, Murray, Chew, \& Farrugia, 2006). iNetSim was designed to be operated solely with the keyboard, alleviating the eye and hand issues faced by vision-impaired students. As a GUI was also available, sighted students were able to use the more traditional drag-drop, mouse-based interface.

Although screen readers are able to translate Microsoft Windows operating systems into speech, the assistive technologies used by the vision impaired instructors and students were not able to access the Linux operating system. Linux skills form an essential part of the courses, so a speech synthesizer for Linux (comprising both hardware and software) was developed specifically for this purpose.

\section{Results}

Evaluation was undertaken at several stages during the project allowing early intervention to address potential problems. The main measures used for the final evaluation were the grades achieved by the vision impaired and sighted students undertaking the same courses plus feedback via student surveys. The student grades indicated the vision impaired students were able to access the materials and mastered the same skills and knowledge as the sighted students.

As the Cisco courses use electronic assessment quizzes, tests, and examinations, these instruments were converted into accessible formats to ensure the vision impaired students sat the same assessment items as the sighted students. The quizzes and tests related to specific modules, whereas the examination was attempted at the completion of all modules in a course. 
The vision impaired students achieved similar ratings to sighted students in quizzes and tests, but took longer to cover the materials in preparation for these assessment events. The vision impaired students were not as confident of their knowledge or skills and spent significant time repeating exercises and re-reading notes. The additional work undertaken by the vision impaired students in preparation for the final examination in each course was observed to be 4-5 times that of the sighted students. The Cisco examinations have a pass mark of $75 \%$ and students must re-sit examinations until they achieve a minimum of $75 \%$ correct answers. Sighted students were expected to gain higher marks than the vision impaired students in the final examination; however, there was no discernable difference in the average scores of the two groups. There was also no difference in the number of examination attempts between the two groups.

In the first intake both groups of students achieved an average of $91.75 \%$. In the second intake the vision impaired students gained an average of $86.90 \%$ compared to $83.99 \%$ for the sighted group in the same assessments (see Table 1).

Table 1: Summary of examination grades

\begin{tabular}{lccc}
\hline Students & $\begin{array}{c}\mathbf{1}^{\text {st }} \text { Intake } \\
\text { Average } \%\end{array}$ & $\begin{array}{c}\mathbf{2}^{\text {nd }} \text { Intake } \\
\text { Average } \%\end{array}$ & $\begin{array}{c}\mathbf{3}^{\text {rd }} \text { Intake } \\
\text { Average\% }\end{array}$ \\
\hline Vision impaired & 91.75 & 86.90 & 87.75 \\
Sighted & 91.75 & 83.99 & 86.30 \\
Difference & 0.0 & 2.91 & 1.45 \\
\hline
\end{tabular}

The results were closer in the third intake, with the vision impaired students achieving an average of $87.75 \%$ compared with $86.30 \%$ for the sighted students. The drop in grades between the first and second intakes was due to Cisco's release of a new version of the e-learning materials and assessments. The third line in the body of Table 1 shows the difference between the grades for the sighted and vision impaired students, measured in percentage grade. All achieved grades were within the 5\% limit set. At no stage over the three intakes did the vision impaired students score grades lower than the sighted students, and in two intakes the average score was slightly higher. The higher scores can be explained by the dedication of the vision impaired students in response to a program specifically designed to improve their skills and employability. These students spent significantly more time reading and completing exercises out of class time than the sighted students.

The Cisco e-learning curriculum in its current form is considered an industry standard and has progressed through more than a decade of updates and enhancements. It is well tried and tested for sighted students. However, the curriculum redeveloped to offer an accessible curriculum alternative has not had the benefit of such in-depth testing and enhancement. To determine how successful the project has been in producing accessible e-learning materials feedback was sought from the vision impaired students undertaking the redeveloped courses. On completion of the courses the vision impaired students submitted completed questionnaires rating several factors, including the accessibility of the original curriculum, accessibility of the redeveloped curriculum, the effectiveness of the equipment provided in the laboratory, the effectiveness of the assistive technologies used (screen reading and text enlargement applications) in accessing materials, and the quality of the delivery of materials by the instructors. Tables 2 and 3 summarize the ratings given.

There was also a noticeable difference in the perception of the totally blind and low vision students as to accessibility of the original e-learning materials prior to re-development. Low vision students have a small amount of usable vision but this amount is so minor they still fall into the legally blind category. Although the range of ratings was the same for these two groups, the average rating for the low vision students was 1.33 with the totally blind averaging a 0.4 rating. Clear- 
ly both groups considered the original Cisco e-learning materials to be poor in accessibility; however those with low vision (but still legally blind) appeared to be able to access a small amount of these materials, explaining the higher average rating.

Table 2: Ratings of accessibility of e-learning materials by vision impaired students

\begin{tabular}{lccc}
\hline & \multicolumn{3}{c}{ Rating $\mathbf{0 =}$ Low, $\mathbf{5}=$ High } \\
\cline { 2 - 4 } Factor & Lowest & Highest & Average \\
\hline $\begin{array}{l}\text { Accessibility of original learning } \\
\text { materials - blind students }\end{array}$ & 0 & 2 & 0.40 \\
$\begin{array}{l}\text { Accessibility of original learning } \\
\text { materials - low vision students }\end{array}$ & 0 & 2 & 1.33 \\
$\begin{array}{l}\text { Accessibility of new learning materials - } \\
\text { blind students }\end{array}$ & 4 & 5 & 4.38 \\
$\begin{array}{l}\text { Accessibility of new learning materials - } \\
\text { low vision students }\end{array}$ & 4 & 5 & 4.30 \\
\hline
\end{tabular}

The average ratings for accessibility of the re-developed e-learning materials across the three intakes for the groups of legally blind students were very similar: 4.38 for the blind students and 4.30 for those with low vision. This was a positive result indicating both the low vision and blind students felt the new materials were greatly improved in accessibility.

Table 3: Ratings of technologies and delivery by vision impaired students

\begin{tabular}{lccc}
\hline & \multicolumn{3}{c}{ Rating 0=Low, 5=High } \\
\cline { 2 - 4 } Factor & Lowest & Highest & Average \\
\hline Equipment used in laboratory & 3 & 5 & 4.33 \\
Assistive Technologies used & 3 & 5 & 4.33 \\
Delivery by instructors & 1 & 5 & 4.55 \\
\hline
\end{tabular}

The majority rated the equipment highly, achieving an average rating of 4.33 out of 5 . Comments included "equipment has been of the highest standard," "computers have been upgraded," "a good consistent quality," "has always been of a high standard and always Cisco corporate networking equipment, what more could you ask for." The instructors rated highly at 4.55 and were supported by favorable comments, including "excellent," "very helpful with vision impairment issues and also questions," and "thorough and comprehensive."

Other factors surveyed related to the students' perception of the value of the skills and knowledge they have gained and their employability at the completion of the courses. Specific questions related to their knowledge of IT and computer networks before and after the training, how much they use the skills and knowledge they have gained, their employability before and now and whether the training had, in their view, improved their effectiveness on the job. The results of the survey are shown in Table 4.

Table 4: Ratings of skills and employability by vision impaired students

\begin{tabular}{lccc}
\hline \multirow{2}{*}{ Factor } & \multicolumn{3}{c}{ Rating 0=Low, 5=High } \\
\cline { 2 - 4 } & Lowest & Highest & Average \\
\hline IT knowledge before & 1 & 3 & 1.35 \\
IT knowledge now & 3 & 4.5 & 3.90 \\
Usefulness of skills obtained & 3 & 4.5 & 4.00 \\
Employability before & 1 & 2 & 1.11 \\
Employability after & 3 & 5 & 3.78 \\
Improved effectiveness on the job & 3 & 5 & 4.35 \\
\hline
\end{tabular}


Most vision impaired participants had a small amount of IT knowledge at the commencement of the project, the majority rating this at level 1 . One student had some prior knowledge and rated himself at level 3. The average IT knowledge before was 1.35 compared to an average of 3.9 at the completion of the training courses. All students noted an increase in the knowledge levels.

Similar ratings were given for the employability of the students, with an average of 1.11 before the training and 3.78 on completion. The students' ability to apply the skills and knowledge was rated highly with an average of rating of 4.0 out of 5 . The vision impaired students also considered their effectiveness on the job was now high, with an average rating of 4.35.

The positive ratings overall were encouraging for the project team and reflected significant success on the part of the vision impaired students. Involvement in the program had increased their self-confidence in their own ability and their ability to perform in an IT role in industry.

The vision impaired students in the three intakes required information and tasks to be organized in a linear fashion. Large amounts of information or complex data presented in tables were particularly difficult for the student to interpret without error. Their activities in undertaking practical exercises were also linear in nature.

Repetition of concepts, materials, and practical application exercises was a key factor in the vision impaired students' comprehension. Experiential learning is highly relevant to vision impaired learners. Additional time needed to be incorporated into the teaching schedule to cover the required repetition. The materials converted into Braille were largely ignored by the students who preferred to repeatedly listen to the audio lectures and use screen reading software to generate voice output from the online textual materials.

Prescriptive parts of the e-learning materials required substantial redesign for accessibility. None of the images or Flash diagrams was accompanied by explanations, with the screen reading applications used by the blind students instead describing the HTML tags. Drag and drop facilities, information presented in tabular formats, online quizzes, examinations and laboratory exercise descriptions and instructions were totally inaccessible. These problems reinforced the need to more fully consider accessibility issues at the curriculum design and development stages. Cisco Systems Inc. is gradually addressing these issues as new versions of the e-learning materials are released.

Another important observation throughout the project has been the amount of time the vision impaired students needed to cover the course materials. The time taken to complete the modules differs between students; however, in general terms the vision-impaired students require at least double the class time allowed for sighted students.

The e-learning environment developed specifically for the vision impaired has been used for both local and remotely located students. The same courses and equipment are used for distance learning as well as traditional classroom learning, thus alleviating the problem of low numbers of science and engineering courses requiring specialist equipment available via distance learning previously observed by Ndahi (2006).

As a direct result of this research just under half of the vision impaired participants have continued with tertiary studies in IT at university. Completion of the four courses gave these students confidence in their ability to successfully complete undergraduate level studies and achieve at similar levels to the sighted students.

\section{Limitations and Future Research}

The nature of the project did not allow for a truly rigorous positivist approach regarding the structure of the two groups of students. Although the two groups of students completed the same 
learning outcomes utilizing the same equipment and some of the same materials (the accessible portion of the Cisco e-learning courses), the vision impaired students did not physically occupy the same classroom at the same time as the sighted students. In addition the sighted students were taught by sighted instructors and the vision impaired students by totally blind instructors.

With regard to hours of tuition the vision impaired students had a total of ten hours per week in the classroom, whereas the sighted students attended only six hours of classes per week to cover the same material. The vision impaired students needed additional time to study each topic in more detail and also required more time than the sighted students completing the remote network design exercises. Under these circumstances it was difficult to determine a weighting that accurately reflected success rates incorporating comparative time spent on each activity.

The project would benefit from broader research in the future on the most effective means of delivering the e-learning materials to different types of learners regardless of their vision capabilities. The instructors noticed that sighted students were regularly utilizing the teaching aids developed specifically for the vision impaired students and the usefulness of these applications and devices as general teaching aids for all students could be investigated.

One of the main observations by the teaching team was that the prescriptive e-learning materials had not been designed with accessibility in mind, and of most concern was the stand-alone nature of the images and flash diagrams which assumed the student had sight. Although alternatives for accessible output were trialed none were able to produce accessible images with the level of granularity required for the technical content (see Murray, 2009, for an extensive description of the devices tested). As a last resort textual descriptions were written for each image, a timeconsuming and inefficient solution. Descriptions need to be incorporated into the web-based materials during the design and development stages highlighting the need for future research into effective means of presenting the informational content of images.

\section{Conclusion}

The successful e-learning environment developed comprised a virtual classroom enabling remote and local delivery of lectures and tutorial exercises, recorded audio lectures, converted learning materials including image descriptions for the graphical components, delivery by vision impaired instructors, manual and computerized teaching aids (the most significant being the pegboard, the network simulation tool and the Linux speech synthesizer), and the remote network laboratory for the configuration and testing of network architectures. From a project management perspective the elements of the e-learning environment for the vision impaired integrated well to provide the level of accessibility required and also give the vision impaired students confidence in their ability to learn and achieve the same learning outcomes as the sighted students. Due to the differing nature of their disability and background, each vision impaired student faced unique challenges and experienced varying achievements related to their disability. The vision-impaired often have other disabilities and health conditions that may affect their progress and consideration must be given to each student as a separate case.

Ratings of the quality of the learning materials appear to have increased over the period of the research. Students enrolled in the courses early in the project generally rated the converted materials lower than students undertaking them later in the project. This could be due to minor enhancements made to the materials on an ongoing basis. The use of vision impaired instructors who had previously undertaken and completed the same learning experience could also have affected the ratings.

An evaluation by the vision impaired students rated the e-learning environment highly and indicated their increase in useful IT knowledge on completion of the Cisco courses. Their confidence in obtaining full-time, relevant employment as a result of the training was positive, but not sub- 
stantial. The use of vision impaired instructors provided evidence that totally blind people can be employed in relevant and meaningful roles, giving much needed confidence to the vision impaired students. Ratings for both sighted and vision impaired instructors were high.

It was found overall that there was no discernable difference in the marks between the sighted students using the original e-learning materials and the vision impaired students using the accessible e-learning environment. This indicates that given a suitable environment and accessible elearning materials, people with acute vision impairment can achieve grades at the same level as the sighted. The majority of the vision impaired students are now either enrolled in bachelor courses or working in IT roles in industry.

\section{Acknowledgements}

The author is sincerely grateful to Dr. Iain Murray (joint Project Manager of the Cisco Academy for the Vision Impaired), the members of the project team and the vision impaired students who dedicated so much of their own time and amazing energy to this project. The delivery of the Cisco training program for the vision impaired in 2007 was partially funded by the Australian Government.

\section{References}

Armstrong, H., \& Murray, I. (2007, June). Remote and local delivery of Cisco education for the visionimpaired. Proceedings of ITiCSE'07, Dundee, Scotland, UK, 78-81.

Boghikian-Whitby, S. \& Mortagy, Y. (2008). The effect of student background in e-learning - longitudinal study. Issues in Informing Science and Information Technology, 5, 107-126. Retrieved from http://proceedings.informingscience.org/InSITE2008/IISITv5p107-126Bogh483.pdf

Fenrich, P. (2005). What can you do to virtually teach hands-on skills? Issues in Informing Science and Information Technology, 2, 47-354. Retrieved from http://2005papers.iisit.org/I28f14Fenr.pdf

Harper, S., Goble, C., \& Stevens, R. (2001). Web mobility guidelines for visually impaired surfers. Journal of Research and Practice in Information Technology, 33(1), 30-41.

Hogan-Royle, T. (2006). For the blind and invisible: A guiding site out of darkness. Proceedings of IADIS International Conference on Web Based Communities, San Sebasitan, Spain, 307-311.

Hope, J., von Konsky, B., Murray, I., Chew, L., \& Farrugia, B. (2006). A Cisco education tool available to the vision impaired. Proceedings of the ACM SIGAccess '06, Portland, Oregon, USA, 235-236.

Hunsinger, D., \& Smith, M. (2008). Factors that influence information systems undergraduates to pursue IT certification. Journal of Information Technology Education, 7, 247-265. Retrieved from http://www.jite.org/documents/Vol7/JITEv7p247-265Hunsinger360.pdf

Kane, S., Shulman, J., Shockley, T., \& Ladner, R. (2007). A web accessibility report card for top international University web sites. ACM International Cross-Disciplinary Conference on Web Accessibility, Banff, Canada, 148-156.

Kelley, P., Sanspree, M., \& Davidson, R. (2000). Vision impairment in children and youth. In Horowitz (Ed.), The lighthouse handbook of vision impairment and vision rehabilitation (pp. 1111-1128). Oxford University Press, New York.

Kinash, S., Crichton, S., \& Kim-Rupnow, W. (2004). A review of 2000-2003 literature at the intersection of online learning and disability. The American Journal of Distance Education, 18(1), 5-19.

Mankoff, J., Fait, H., \& Tran, T. (2005). Is your web page accessible? A comparative study of methods for assessing web page accessibility for the blind. Proceedings of CHI 2005, Portland, Oregon, USA, 4150 . 
McEwan, T., \& Weerts, B. (2007). ALT text and basic accessibility. Proceedings of the 21st British HCI Group Annual Conference on HCI 2008, Lancaster UK, 71-74.

Moriarty, M. (2007). Inclusive pedagogy: Teaching methodologies to reach diverse learners in science instruction. Equity \& Excellence in Education, 40(3), 252-265.

Murray, I. (2009). Instructional e-learning technologies for the vision impaired. Ph.D. Thesis, Curtin University of Technology. Retrieved October 24, 2009, from Curtin University of Technology Digital Theses.

Ndahi, H. (2006). The use of innovative methods to deliver technology education laboratory courses via distance learning: A strategy to increase enrollment. Journal of Technology Education, 17(2), 33-42.

Pearson, E., \& Koppi, T. (2002). Inclusion and online learning opportunities: Designing for accessibility. ALT-J, 10(2), 17-28.

Sánchez, J. (2007). A model to design interactive learning environments for children with visual disabilities. Education and Information Technologies, 12, 149-163.

Shore, D. I., \& Klein, R. M. (2001). On the manifestations of memory in visual search. Spatial Vision, $14(1), 59-75$.

Spence, C., Kettenmann, B., Kobal, G., \& McGlone, F. P. (2001). Shared attentional resources for processing visual and chemosensory information. Journal of Experimental Psychology, 54(3), 775-783.

Sprenger, M. (1999). Learning and memory: The brain in action. Alexandria, VA, USA: ASCD.

Sweat-Guy, R., \& Wishart, G. (2008). A longitudinal analysis of the effects of instructional strategies on student performance in traditional and e-learning formats. Issues in Informing Science and Information Technology, 5, 149-163. Retrieved from http://proceedings.informingscience.org/InSITE2008/IISITv5p149-163Sweat430.pdf

Thesen, T., Vibell, J. F., Calvert, G. A., \& Osterbauer, R. A. (2004). Neuroimaging of multisensory processing in vision, audition, touch, and olfaction. Cognitive Processing, 5(2), 84-93.

Thompson, T., Burgstahler, S., \& Comden, D. (2003). Research on Web accessibility in higher education. Journal of Information Technology and Disabilities, 9(2). Retrieved July 13, 2009 from http://people.rit.edu/easi/itd/itdv09n2/thompson.htm

Yip, M. (2004). Using Web-CT to teach courses online. British Journal of Educational Technology, 35(4), 497-501.

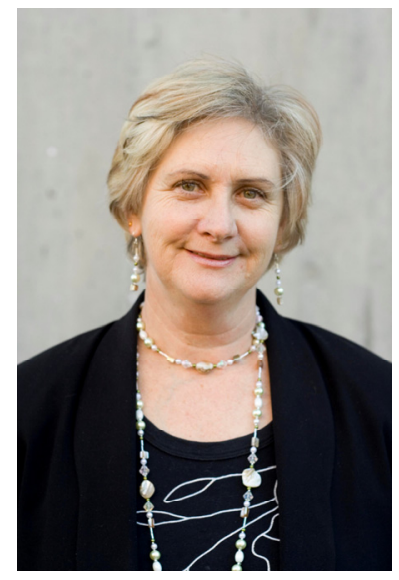

\section{Biography}

Dr Helen Armstrong teaches and researches within the School of Information Systems at Curtin University of Technology in Western Australia where she coordinates Higher Degrees by Research. Her research interests focus on the integration of social and technical aspects of IT including accessibility issues in IT, creative problem solving in IT, social network analysis and computer crime and network security. Helen manages research in the Cisco Academy for the Vision Impaired together with Dr. Iain Murray at Curtin University, and also works with law enforcement and defense organizations in the areas of information warfare and cyber-crime. 